\title{
The Impact of Legislative Deterrence Measures on the Number of Asylum Applications in Switzerland $(1986-1995)^{1}$
}

\author{
Thomas Holzer \\ Universität Bern \\ Gerald Schneider \\ Universität Konstanz \\ Thomas Widmer \\ Universität Zürich
}

In the late eighties and early nineties, almost all Western European nations adopted an increasingly restrictive policy towards the growing number of asylum seekers. We develop a push-and-pull model and evaluate whether these newly created deterrence measures had a significant impact on the number of asylum applications in Switzerland. The statistical tests in the form of Box-Tiao intervention analyses shows that states are only partially able to control global migration. We particularly demonstrate that only one of the unilateral measures adopted by the Swiss government reached the main goal and led to a substantial reduction in the number of applications in 1990. Further, legal reforms did not affect the number of asylum requests of refugees fleeing from a violent conflict in the neighborhood of the host country.

Asylum policy has been heading the political agenda in Western Europe since the late 1970s when the unexpected influx of Vietnamese refugees and decreasing transportation costs paved the way towards intensified global

'This article is part of a larger research project on migration policy in OECD countries and Switzerland. We kindly acknowledge the financial support of the Swiss National Science Foundation (Special Program in Migration Studies, grant no. 4039-044836/1), the Foundation 'Bevölkerung, Migration, Umwelt' and the Berner Hochschulförderung. None of these institutions is in any way responsible for our interpretations. Previous versions of the paper have been presented at a conference of the research group on migration of the German Association for Political Science, Münster, February 15-16, 1997 and at the 25th Joint Session of Workshops of the European Consortium for Political Research, Bern, Switzerland, February 28 - March 4, 1997. We would like to thank the participants for their comments, especially Wolf-Dieter Eberwein, Han Dorussen, Thomas König, and one anonymous reviewer. 
migration. Although the OECD member states were generally less exposed to mass refugee flows than many developing countries, some observers spoke of the 'global migration crisis' (Weiner, 1995) and engaged in historical speculations, drawing analogies with the Völkerwanderung of the first millennium (Enzensberger, 1994).

In Western Europe, it was especially the growing number of asylum applications which provoked political reactions. Most European nation states have moved towards a more restrictive formulation and interpretation of their asylum policies since 1980. In this article, we evaluate the impact of the deterrence measures with which one relatively important host country, Switzerland, tried to lower the number of asylum applications (for a discussion of the political process, see Linder, 1994). This country has been confronted since the early 1980s with a steep increase in the number of applications which jumped from 1,882 in 1979 to 41,629 in 1991. A further development was that the origin of the vast majority of asylum seekers changed substantially during this period. No more than 10 percent of all asylum applications originated from countries outside of Europe before 1980. By 1982, over 70 percent of the Swiss asylum applicant pool consisted of persons originating from countries in Asia, Africa, the Middle East and Latin America.

Unsurprisingly, asylum policy has become one of the most fiercely debated issues in Swiss domestic politics. Two basic positions are at loggerheads. On the liberal side of the political spectrum, the left and the greens consider the existing legal framework too strict and inhumane and demand at least temporal integration of asylum seekers. The bourgeois majority, formed by three different center-right parties in both the parliament and government, conversely tries to make Switzerland a less attractive country for asylum seekers. The political contest has resulted in the adoption of seven restrictive measures. ${ }^{2}$ Our study tries to show whether the new rules reached their goals and led to a substantial reduction in the number of asylum applications.

Our evaluation of the Swiss case makes three major contributions to the theoretical literature on global migration and asylum policymaking. First, we challenge the widespread view (see, e.g., Freeman, 1992; Hollifield, 1994; and

2The main measures include a modification of the asylum law (1983), a legislation with an executive order which provisionally created a new federal office to administer refugee and migrant programs (1985), an asylum law modification of June 1986, two simultaneously adopted ordinances, a so-called urgent federal resolution (1990), and two ordinances in 1991. Urgent federal resolutions stand for proposals that need parliamentary approval, but are not subject to a popular referendum. For a legal discussion of Swiss asylum law, see Kälin, 1990 and Achermann and Hausamman, 1991. 
Weiner, 1995) that individual states are unable to deal with global migration and that the deterrence measures governments tend to introduce are largely ineffective. Our statistical tests in the form of Box-Tiao intervention analysis (Box and Tiao, 1975; see also McCleary and Hay, 1980; Bowerman and O'Connell, 1993; Orwin, 1997) show that nation states are not prisoners of the internationalization of migration (for a similar criticism, see Joppke, 1997, 1998). On the contrary, government regulation can considerably affect the number of asylum requests even in the absence of a formal restrictive regime between industrialized states. Hence, the most prominent unilateral deterrence strategies pursued by Switzerland were effective and apparently deterred a considerable number of refugees from applying for asylum in Switzerland.

However, this insight has to be qualified considerably because even the most restrictive measures did not influence refugee inflows from certain states. While the reforms of the early 1990s greatly affected the number of applications from geographically and culturally distant nations, no such impact was observed for applications from the former Yugoslavia. Furthermore, the restrictive measures adopted throughout the 1980s did not have the deterrent effect that the government and the leading parties had wished for.

Second, the article partly supports the conviction that global migration is, to some extent, a volatile process which is beyond the control of individual nation states. The detailed analysis of the development in the number of asylum applications from specific sender countries demonstrates the overriding influence of push over pull factors. In the Turkish case, for instance, inflation is a major determinant of the number of asylum requests. The country-specific analyses that we conducted for the most important sender countries show that the impact of the deterrence measures can take quite different forms.

Third, we show that the number of asylum applications and the admission ratio are interrelated. This indicates that the Swiss authorities changed the interpretation of the reasons for recognizing refugees without altering the legal refugee status. At least rhetorically, the Swiss government still adheres to the humanitarian tradition that the country enjoyed in the past and argues that the "reforms" only allow to separate "false" from "real" refugees (Bundesrat, 1990). The link between the inflow of refugees and the admission ratio suggests, more broadly, that unilateral measures undermine the liberal international asylum regime dramatically. Since governments apparently tend to make their asylum decisions dependent on issues other than the motivations of the individual asylum seekers to flee their home country, a uniform application of the global norms is no longer guaranteed. 
The article presents first an overview of the historical background of the international asylum regime and then reviews the theoretical literature. We subsequently derive a set of partly contradicting hypotheses from a push and pull model. Next, our research strategy is outlined and we describe the ways in which we operationalize our variables. Some descriptive material of the development of asylum applications is presented as well as the results of the time series models. The conclusion summarizes our findings and discusses, in the light of mass flight from Kosovo, under what conditions unilateral deterrence measures can be successful. We present details of the statistical models in the appendix.

\section{ASYLUM POLICY MAKING: BACKGROUND AND THEORETI- CAL CONSIDERATIONS}

All Western European nations, including Switzerland, joined the Geneva Convention on the status of refugees by the 1950s and accepted the key elements of the international asylum regime despite occasional reservations. ${ }^{3}$ One drawback of the current definition is the considerable discretion that authorities possess. Until the end of the 1970s, this vagueness was generally interpreted in favor of asylum applicants. The tolerant attitude probably was due to two main reasons. First, the overall number of asylum applicants had not reached a level which the domestic populations considered to be critical. Second, the Western European public generally welcomed refugees from communist regimes; this was the vast majority of all refugees at that time (Miles and Thränhardt, 1995). The public's sympathy could have motivated their governments to recognize practically all of these asylum seekers.

Yet, the generous attitude started to wane in the 1980s when increasing numbers of asylum applications and the changing origins of the applicants provoked harsh reaction. In 1989, 75 percent of the Swiss population identified the asylum issue as an urgent policy problem (Risi, 1989). The rising xenophobia also found its expression in an increasing number of personal attacks on asylum seekers. The violence culminated in the murder of refugees in some German cities (Krell, Nicklas and Ostermann, 1996).

All over Europe, important parts of the political elite were responsive to the demand that the number of asylum seekers should be reduced and a more restrictive policy adopted. Germany, for instance, changed its asylum law several times in the period from 1980 to 1995 (Nuscheler, 1995:146-148) and

3The two major exceptions are Portugal and Spain who signed the Convention in 1960 and 1978 , respectively. 
assisted in the creation of restrictive measures at the level of the European Union.

The important theoretical question is whether such moves toward an exclusionary policy reach their goals. In a juridical perspective, Carlier (1997:279) describes the respective choice as a trade-off and writes, ". . . the conflict between various interpretations of the refugee is the real challenge, the clash between legal principles and their effectiveness." Critics of the nationalist course (e.g., Freeman 1992, Hollifield 1994, Weiner 1995) have argued that unilateral policies will remain at best unsuccessful since migration is a global phenomenon. In their perspective, such measures will only put the burden on other nations' shoulders and cannot influence the desire of those individuals who wish to flee a crisis-ridden area. Proponents of this perspective draw on the literature on globalization and international regimes and contend that the international human rights frame weakens the state. A further argument is that the simultaneous decline of transportation costs and the increase in the number of human disasters has created a migration problem of previously unknown proportion. Attempts of nation states to influence the inflow of refugees are not the least weak because of the increasingly open borders and the difficulties in enforcing policies of migration control. A final argument that is often made in this context refers to the North-South welfare gap, which makes the industrialized world an attractive destination for an ever-increasing number of people.

This hypothesis has been criticized during the past few years by a school of thought which stresses the domestic underpinnings of migratory policies. Joppke (1997, see also 1998) perceives the nation state as the main actor and believes that especially majoritarian systems are able to close their borders towards immigrants. Lahav (1998) reiterates this point and convincingly argues that the actor 'state' has to be disaggregated to understand the possibilities and limitations of immigration control. Money (1997) shows how local constituencies are able to force politicians into supporting restrictive measures. Spörndli, Holzer and Schneider (1998) equally demonstrate that politicians adapt their behavior to the wishes of their supporters in the asylum domain. This is important, insofar as a clear majority has been asking for more restrictive asylum policies in Western Europe since the beginning of the 1980s. The legislative reforms are thereby quite often introduced under the argument that the humanitarian substance of the asylum laws remains unchanged. 


\section{Theoretical Background}

The model that we develop refers to the discussion of state control in the asylum domain. We systematize the contending views in an analytical framework that is inspired by the main theoretical concept in the migration literature, namely the idea that both "push" and "pull" factors simultaneously contribute to migration (see, e.g., Zimmermann, 1996). Push factors are the individual motivations to leave an unbearable situation in what is technically often considered a "sender" country. War, famine, environmental degradation or political persecution of ethnic or religious minorities are some of the reasons that are mentioned in this context. These factors stand, by and large, for the view that global migration is a process that governments can hardly control. Pull factors stand for the determinants that draw migrants from a sender to a specific receiving country or that deter them from entering a state. One can imagine the economic situation and the legal system in the receiving state, or the geographic proximity between sender and receiving nation, to be typical pull factors (for an introduction, see Nuscheler, 1995).

The main drawback of this dual concept is the lack of solid foundations that reach beyond the level of a purely metaphorical analysis. Although some authors (e.g., Nuscheler, 1995; Weiner, 1995) try to systematize the loose list of determinants, no clear and testable hypotheses are formulated (see Hammar, 1987; Brochmann, 1993; Collinson, 1993; Fassmann and Münz, 1994; Hollifield, 1994; Heckmann and Bosswick, 1995). In this article, we want to make a step toward a formalization of the push and pull factors (see Freeman, 1992; Money, 1997).

While the real and potential asylum applications constitute the demand side, the supply of asylum is influenced by a mainly domestic struggle over the orientation of a country's asylum policy. This is not to say that a country's asylum policy is influenced by internal factors alone (for a formal model of interstate asylum cooperation, see Holzer and Schneider, 1999). On the contrary, a statistical study by Schneider and Zanger (2000) shows that a deteriorating human rights situation or the outbreak of a militarized conflict are both associated with higher numbers of asylum applications from the concerned sender state. The study also confirms the (new) version of the classic Hirschmanian hypothesis that high levels of public protest (voice) is positively correlated with the outflow of refugees (exit). The number of immigrants from a sender country already residing in the host country also influences the number of applicants in a positive fashion (Schneider and Zanger, 2000). 
The following functional form summarizes our theoretical considerations on the factors that influence the number of asylum requests.

$$
\text { REQ }=f(D E T E R R, E C O N, \text { INTSYST, RECOGN })
$$

where REQ stands for the number of asylum requests, DETERR represents the existence of current deterrence measures, and ECON denotes the state of the economy in both the target and sender countries. Further, INTSYST are key events in the international system such as a civil war that might cause a significant number of refugees, and RECOGN denotes the recognition ratio for asylum seekers. We expect these exogenous variables to influence the number of asylum requests only after some months. Although the explanatory variables should accordingly be indexed with a time subscript, we omit such a specification because the length of the time lags is beyond theoretical considerations and does not need to be the same for all independent variables. The number of lags after which the exogenous variables have an impact on the number of asylum requests will be estimated within the model.

Among the right hand side variables of equation (1), INTSYST refers to push factors for migration and asylum. As already indicated, violations of basic human rights and other indicators of a deteriorating political and economic situation in the sender countries stimulate migration. We therefore expect a positive relationship between the outcome variable and INTSYST. The economic variables can in principle refer to both push and pull factors for migration. But we include in our analysis on the aggregate level only economic variables of the receiving country, expecting them to have a positive impact on the number of asylum requests. The better the economic situation in a certain country, the more attractive it is to apply for asylum there. The other two independent variables also belong to the category of pull factors. It seems obvious on the one hand that 'successful' deterrence measures, everything else being equal, should decrease the number of applications. On the other hand, high recognition rates in the past in a certain nation are a strong incentive for asylum seekers to apply to that country. Moreover, the settlement of refugees from a particular country possibly creates the nucleus of a social network that might attract other compatriots.

\section{RESEARCH STRATEGY AND DEFINITION OF VARIABLES}

The push and pull model postulates that the number of asylum applications is a consequence of both domestic and international factors. In the following, 
we test these conflicting hypotheses in a time series analysis of the developments in Switzerland. We pay particular attention to the impact of legal measures that the Swiss authorities implicitly or explicitly adopted to lower the number of asylum applications. The analysis focuses on this country because of its relative significance in Western European asylum policymaking. Besides Germany and the Netherlands, Switzerland always belonged, relatively speaking at least, to the main host countries. The Swiss case is also interesting because the country is known for its humanitarian tradition in asylum policymaking.

The statistical tests are restricted to the period from 1986 to $1995 .{ }^{4}$ The dependent variable consists of the monthly number of asylum applications in Switzerland. Among the different predictors, the systemic trends are the most difficult concepts to operationalize. In our opinion, it does not make sense, for two reasons, to create a global conflict indicator on a monthly basis that would measure the potential for refugee flows. First, we lack a sound event data set that would cover all trouble spots of the world simultaneously. Second, and more importantly, not all comparable conflicts have similar potential consequences for Switzerland, since the possibility of reaching Western Europe varies considerably among refugees from different locations. The different and changing origin of asylum seekers creates another analytical problem. This raises a fundamental question: is it possible to influence the total number of asylum seekers originating from all countries through legal revisions, as the Swiss government intended? Or, to put it the other way around, are there such strong country-specific trends in application numbers that the artificial aggregate is not more than a chimera? In order to obtain at least a partial answer to this question, we will estimate different models for the number of the total requests per month by omitting the INTSYST variable.

As economic indicators, we consider the monthly inflation and unemployment rates in Switzerland. Unfortunately, the often-made argument that migration from Third World countries to Western Europe basically occurs because of the considerable welfare gap between these two regions is beyond the scope of our framework (see Schneider and Zanger, 2000). First, welfare is commonly expressed by either the Gross National Product (GNP) or the Gross Domestic Product (GDP), which is measured on a quarterly rather

4To perform a sensible statistical analysis, we need uninterrupted monthly data of both the number of asylum applications and the recognition ratio. This type of data does not exist for dates earlier than January 1986 since nine months of data on the recognition ratio were lost in the Federal Office for Refugees. The monthly number of applications can be traced back to the early 1980 s. 
than monthly basis. Second, differences in GNP or GDP between highly industrialized nations and developing countries remained more or less constant during the past decade. Quite obviously, it would be impossible to explain variation in asylum requests by a nearly constant exogenous time series. We define, in accordance with the Federal Office for Refugees, the recognition rate (RECOGN) as the share of positively decided applications relative to all decisions. Finally, deterrence measures (DETERR) in the form of revised asylum laws containing restrictive elements are modeled as dummy variables that take the value of one after a revision was put into force.

\section{Methodology}

The enactment of a legal revision is in technical terms an intervention and can be regarded as an exogenous shock on the time series under consideration. An appropriate statistical tool for this purpose is an intervention design that follows the approach pioneered by Box and Tiao (Box and Tiao, 1975; see also McCleary and Hay, 1980; Bowerman and O'Connell, 1993; Orwin, 1997). The so-called Box-Tiao approach employs a specific time series design, the ARIMA (AutoRegressive Integrated MovingAverage) method, to model the time series under consideration. 5 This procedure forces a researcher to fit an ARIMA model to the time series before the estimation of the impact that the intervention could have had. This transforms the initial series into white noise by removing its autoregressive, integrated or moving average components. Accordingly, ARIMA impact models also include a noise term $\mathrm{N}_{\mathrm{t}}$. In their most general form, they can be summarized as follows:

$$
Y_{t}=f\left(I_{t}\right)+N_{t}
$$

where $Y_{t}$ denotes the initial time series and $I_{t}$ stands for the intervention.

The impact of an intervention on a time series (i.e., the functional form f) can theoretically take four forms. The effect can be either temporary or permanent. In addition, it can occur in both of these cases either in an abrupt or a gradual manner, making abrupt-temporary, abrupt-permanent, gradualtemporary, and gradual-permanent equally viable options. Moreover, these effects possibly start to take place only after a certain lag.

${ }^{5}$ ARIMA makes it possible to model a series with its own past values and past errors of the estimation. The underlying assumption of ARIMA modeling is that any series can be conceived as an integrated stochastic process. 
An intervention input is always modeled as a dummy variable. In the case of a temporary effect, the predictor takes the value one for the period during which the intervention affects the time series. Before and after this intervention period, the variable takes the value zero. A temporary effect is referred to as a pulse input. The dummy variable for a permanent effect is called a step input. It takes the value zero in the preintervention period and the value one in the postintervention phase.

In order to measure the impact of an exogenous time series on the number of asylum applications, a slightly different model has to be employed. The methodology remains within the ARIMA framework, but transfer functions instead of intervention functions are estimated. Transfer functions indicate a causal relationship between the exogenous and endogenous series. The transfer function method allows not only the determination of the functional form of the impact that the independent series $\mathrm{X}$ has on the endogenous variable $\mathrm{Y}$, but also enables the estimation of the number of lags after which the impact possibly starts to take place. The statistical methods and their properties are described in more detail in the appendix.

Our statistical analysis refers to monthly data and covers a period of ten years. These 120 observations represent a sufficiently large number to perform a time series analysis. We test our hypotheses for both an aggregated time series and for applications from six individual countries. We expect the impact of the independent variables to be rather weak in the aggregate, since conflicting developments in different countries may wash out important effects.

\section{EXPLAINING THE CHANGE IN THE NUMBER OF ASYLUM APPLICATIONS}

\section{Descriptive Findings}

This section analyzes the impact of legal measures on the number of asylum applications. As Figure 1 shows, only the measures adopted in the 1990s seem to have had the desired deterrent effect. Until the 1980s, the number of applications is steadily growing. This explains the hectic legislative activity throughout this period.

Another peculiarity in the development of asylum requests put forward in Switzerland is the considerable and changing share of different sender countries over the time period under consideration. While most asylum seekers first came from Sri Lanka (McDowell, 1996) or Turkey, the 1990s witnessed an influx of refugees from the former Yugoslavia. Especially the latter development causes analytical problems. As Figure 1A shows, the ups and 
downs in the monthly time series of asylum applications after the middle of 1990 are almost completely determined by the number of people originating from former Yugoslavia; in other words, the different civil wars in the Balkans transformed the demand for asylum during this time period.

Figure 1.

Number of Monthly Asylum Applications in Switzerland, 1986-1995

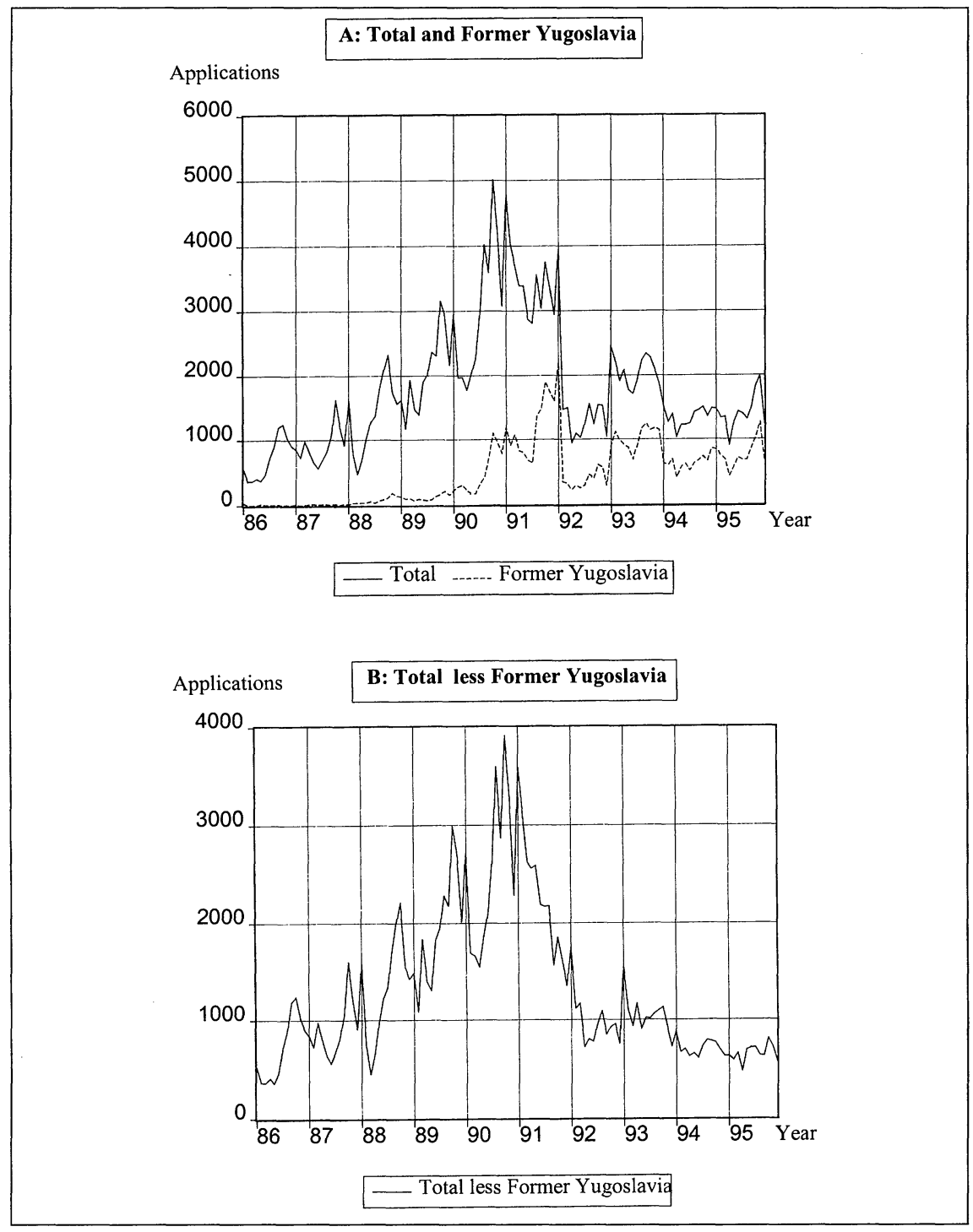


If we remove those applicants from our analysis, the decrease in the number of asylum requests already begins by the end of 1990, which coincides with the most severe legal change of the early 1990s. In October 1990, the Federal Council and the Parliament adopted a so-called urgent federal resolution (see Spörndli, Holzer and Schneider, 1998). Figure 1B accordingly shows that the peak in 1993 of the original time series disappears as a consequence of this step.

We argue that to consider these applications separately can be justified from a theoretical point of view. The violence of the Yugoslavian civil wars, with all their human rights violations and systematic atrocities, was undoubtedly an immense push factor. No similar migration crisis has originated in Europe since the mass geographical reallocation of people at the end of World War II. In addition, the geographical proximity of the former Yugoslavia to Switzerland constituted a very strong pull factor. The relatively large number of Yugoslavian workers already residing in Switzerland before the escalation of the conflicts was another factor that contributed to this trend. It seems consequently plausible to us that, if a conflict reaches a certain level of violence, threatened people flee their country in order to seek refuge somewhere else. If the fleeing population happens to know that compatriots live in a certain country within their reach, it will most likely try to get there regardless of the economic situation or the legal system in that country. Since deterrence measures affect former Yugoslavian asylum applicants to a lesser extent, these refugees ought to be treated as a special case in our analysis.

The importance of a country-based analysis is further substantiated if we analyze the number of asylum applications from other 'typical' sender states. Figure 2 shows the development for three categories of countries. The first category includes Sri Lanka and Turkey, the two main sender countries over the total observation period. In the second category we have the former Yugoslavia and Lebanon as examples of sender countries that had, during the investigation period, both very low and very high numbers of requests per month. The last two states, Angola and Vietnam, represent sender countries with a continuous share of the total number of applications, albeit at different levels.

According to the plots in Figure 2, the intervention by the Federal Council in October 1990 seems to have had a permanent effect on the number of requests from asylum seekers originating from Lebanon and Turkey. The plot of Angolan applications suggests that the impact of the intervention disappeared in 1993. In the Sri Lankan case, the effect of the intervention seemed 
Figure 2.

Monthly Number of Asylum Applications in Switzerland, different Sender Countries

a) Constant migration, main sender countries: Sri Lanka, Turkey

b) Temporary migration influxes: Former Yugoslavia, Lebanon

c) Minor sender countries: Angola, Vietnam
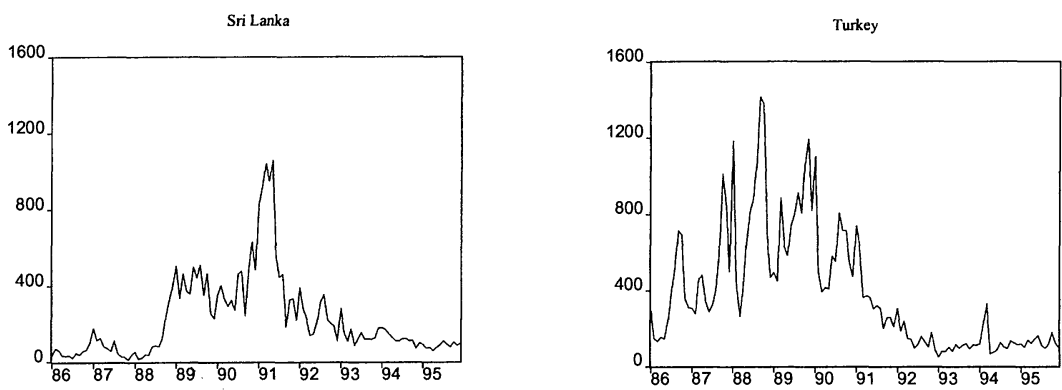

b) Scale ranges from 0 to $2 ' 500$
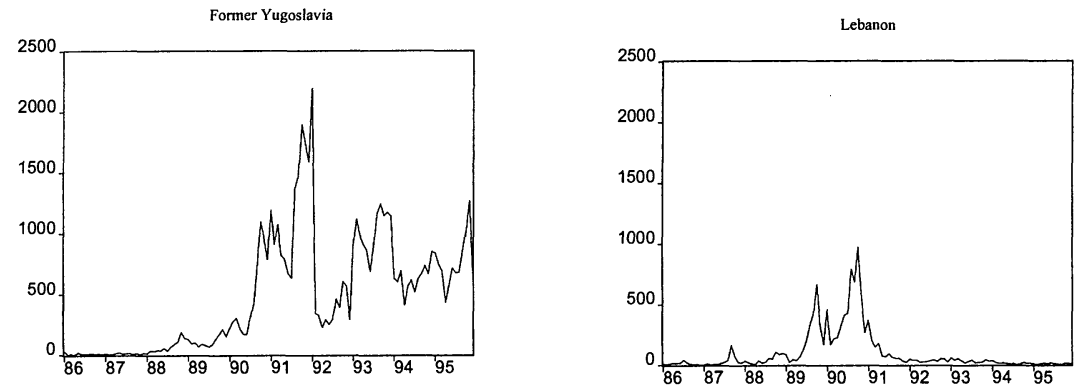

c) Scale ranges from 0 to 200
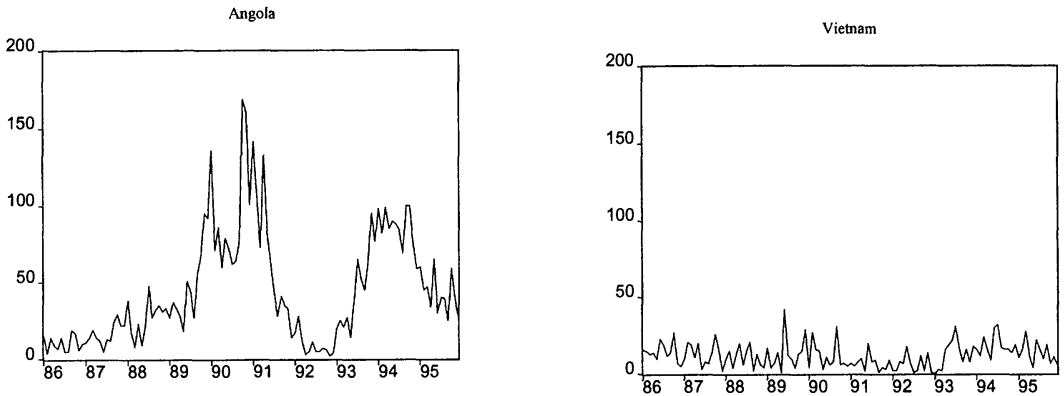

(Note that figures a), b), and c) have different scales)

a) Scale ranges from 0 to $1,600 \mathrm{~b}$ ) Scale ranges from 0 to 2,500 c) Scale ranges from 0 to 200 
TABLE 1

ANNuAl Number of ASYlum APPLICATIONS ANd Recognition Rates IN SWITZERLAND, 1978-1995

\begin{tabular}{cccccc}
\hline \hline Year & $\begin{array}{c}\text { Number of Asylum } \\
\text { Applications }\end{array}$ & $\begin{array}{c}\text { Recognition } \\
\text { Rate }\end{array}$ & Year & $\begin{array}{c}\text { Number of Asylum } \\
\text { Applications }\end{array}$ & $\begin{array}{c}\text { Recognition } \\
\text { Rate }\end{array}$ \\
\hline 1978 & 1,388 & 90.2 & 1987 & 10,913 & 9.1 \\
1979 & 1,882 & 90.5 & 1988 & 16,726 & 7.1 \\
1980 & 3,020 & 66.1 & 1989 & 24,425 & 4.9 \\
1981 & 4,226 & 94.1 & 1990 & 35,836 & 4.9 \\
1982 & 7,135 & 74.9 & 1991 & 41,629 & 3.0 \\
1983 & 7,886 & 48.6 & 1992 & 17,960 & 4.6 \\
1984 & 7,435 & 24.4 & 1993 & 24,739 & 14.7 \\
1985 & 9,703 & 14.2 & 1994 & 16,134 & 12.5 \\
1986 & 8,546 & 12.4 & 1995 & 17,021 & 14.9 \\
\hline \multicolumn{7}{l}{ Source: Federal Office for Refugees, Statistical Services }
\end{tabular}

to occur only after a lag of some months. Finally, Vietnamese asylum seekers did not seem to take notice of the more restrictive asylum laws in Switzerland. This is probably due to the extremely large recognition rate for Vietnamese refugees. Moreover, the average recognition rate for people from that country increased from 48 percent before the intervention to 92 percent after the resolution. Table 1 summarizes the developments of annual applications rates for the selected countries numerically.

Unfortunately, we do not possess data on specific countries before 1986. The six countries in Table 2 account for approximately 70 percent of the total number of asylum applications in Switzerland between 1986 and 1995. As the plots in Figure 2 indicate, the temporal development of the number of applications from the selected countries is rather different. Moreover, Table 2 shows that the relative importance of the six sender countries also changed over time. Until 1990, Turkey accounted for almost half of all applications and was by far the most important sender country. After this year, the former Yugoslavia moved into Turkey's former position, whereas the latter country now accounted for less than 10 percent of the overall number of applications. During the entire ten years, Sri Lanka's importance was always second or third, but its share of the number of requests varied considerably. It started in 1986 at a level of 7 percent, peaked in 1989 at 20 percent and dropped again to 6 percent in 1995. Lebanon was usually a less important sender country, but in 1989 and 1990 it accounted for more than 10 percent of all applications. Finally, Angola and especially Vietnam are examples of less important sender countries.

As previously outlined, the former Yugoslavia represents another deviating case that highlights the direct impact of political developments as a push factor. The plot of the applications from the former communist country indi- 
TABLE 2

Number of Annual Asylum Applications from Certain Countries (IN PARENTHESES SHARE OF ALL APPLICATIONS IN \%) ${ }^{\mathrm{a}}$

\begin{tabular}{lcccccccc}
\hline \hline & & Former & & \multicolumn{5}{c}{ Sri } \\
Year & Total & Yugoslavia & Angola & Lebanon & Lanka & Turkey & Vietnam Countries \\
\hline 1986 & 8,546 & 119 & 125 & 145 & 599 & 4,080 & 175 & 3,303 \\
& & $(1.39)$ & $(1.46)$ & $(1.70)$ & $(7.01)$ & $(47.74)$ & $(2.05)$ & $(38.65)$ \\
1987 & 10,913 & 130 & 197 & 375 & 895 & 5,825 & 157 & 3,334 \\
& & $(1.19)$ & $(1.81)$ & $(3.43)$ & $(8.20)$ & $(53.88)$ & $(1.44)$ & $(30.55)$ \\
1988 & 16,726 & 819 & 322 & 533 & 1,519 & 9,689 & 129 & 3,715 \\
& & $(4.90)$ & $(1.93)$ & $(3.19)$ & $(9.08)$ & $(57.92)$ & $(.77)$ & $(22.21)$ \\
1989 & 24,425 & 1,365 & 575 & 2,485 & 4,806 & 9,387 & 168 & 5,639 \\
& & $(5.59)$ & $(2.35)$ & $(10.17)$ & $(19.68)$ & $(38.43)$ & $(.69)$ & $(23.09)$ \\
1990 & 35,836 & 5,671 & 1,137 & 5,497 & 4,769 & 7,201 & 139 & 11,422 \\
& & $(15.82)$ & $(3.17)$ & $(15.34)$ & $(13.31)$ & $(20.09)$ & $(.39)$ & $(31.87)$ \\
1991 & 41,629 & 14,198 & 796 & 1,357 & 7,343 & 4,311 & 86 & 13,538 \\
& & $(34.11)$ & $(1.91)$ & $(3.26)$ & $(17.64)$ & $(10.36)$ & $(.21)$ & $(32.52)$ \\
1992 & 17,960 & 6,265 & 105 & 434 & 2,791 & 1,879 & 76 & 6,410 \\
& & $(34.88)$ & $(.58)$ & $(2.42)$ & $(15.54)$ & $(10.46)$ & $(.42)$ & $(35.69)$ \\
1993 & 24,739 & 12,267 & 543 & 410 & 1,741 & 1,146 & 160 & 8,472 \\
& & $(49.59)$ & $(2.19)$ & $(1.66)$ & $(7.04)$ & $(4.63)$ & $(.65)$ & $(34.25)$ \\
1994 & 16,134 & 7,632 & 1,029 & 180 & 1,486 & 1,584 & 221 & 4,002 \\
& & $(47.30)$ & $(6.38)$ & $(1.12)$ & $(9.21)$ & $(9.82)$ & $(1.37)$ & $(24.80)$ \\
1995 & 17,021 & 9,210 & 511 & 126 & 1,035 & 1,499 & 162 & 4,478 \\
& & $(54.11)$ & $(3.00)$ & $(.74)$ & $(6.08)$ & $(8.81)$ & $(.95)$ & $(26.31)$ \\
Total & 213,929 & 57,676 & 5,340 & 11,542 & 26,984 & 46,601 & 1,473 & 64,313 \\
Average & & $(26.96)$ & $(2.50)$ & $(5.40)$ & $(12.61)$ & $(21.78)$ & $(.69)$ & $(30.06)$ \\
\hline
\end{tabular}

Source: Federal Office for Refugees and own calculations

a Note: that the sum of shares may not correspond to $100 \%$ due to rounding errors.

cates that the influx to Switzerland took place in at least three waves. The first, occurring between the middle of 1990 and 1991, was probably due to the growing discrimination against ethnic Albanians in the province of Kosovo. In April 1990, the Serb authorities took over control of the police in Kosovo, initiating a wave of discrimination and human rights violations by the police force (Roggemann, 1993). The second wave began in the second half of 1991 with the secession attempts by the former Yugoslavian states Slovenia and Croatia. After their unilateral declarations of independence in June 1991, the Yugoslav government sent the Yugoslav People's Army to Slovenia and Croatia. This move initiated a brief dispute in the former and an atrociously violent war in the latter state. Interestingly, the number of asylum requests sharply declined at the beginning of 1992 . The agreement between Croatia and Serbia to station UN peacekeepers could explain this development. This peaceful settlement, however, could not prevent the escalation in Bosnia where the third and bloodiest civil war was about to begin. The first victims of this conflict only arrived in Switzerland with the third wave, which began in 1993 . 


\section{Statistical Analysis}

This section examines possible causes of the sudden drop in the number of applications in Switzerland. One reason for this development could be that the economic recession deterred potential asylum applicants from traveling to Switzerland. Another possibility would be that the legal measures undertaken by the Swiss government had the deterrent effects that the bourgeois majority in the federal government desired, namely a reduction in the number of applications. Third, one could suspect that the situation in the main sender countries changed considerably, thereby lowering the demand for asylum. This would imply that other Western European nations observed a decline in asylum requests at the same time. We rule out this last possibility immediately because the number of asylum applications in Germany - a country that can be considered as a close substitute to Switzerland for potential asylum seekers - almost doubled in 1992 compared to 1991.

We address now the second possible cause of the sharp decline in asylum requests - the deterrent impact of new or reformed legislation. Since the urgent resolution of October 1990 remained in force until the end of our investigation period, the intervention should have caused a permanent effect on the time series of asylum applications in either an abrupt or gradual fashion. The two types of effects lead to very different interpretations. A gradual decrease in applications after October 1990 would imply that it takes a certain time until potential asylum seekers obtain the relevant information about the new legal procedure. Furthermore, this time span probably differs across countries if one considers the varying geographical and cultural distances between Switzerland and the sender countries. On the other hand, the restrictions of the asylum law could have been anticipated by a large part of the potential asylum seekers because the national parliament had previously discussed the new measures at length. Moreover, the parliamentary debates have been reported in the mass media. An early anticipation of deterrence measures could have caused an abrupt decrease in requests, especially once the new legal framework was enacted. A close visual inspection of Figure 1B does not clearly reveal whether the decline in requests shows an abrupt or gradual pattern. We therefore estimated a model for both types of intervention impacts. The results of those estimations and the results of two multivariate models are shown in Table 3 (see the Appendix for further explanation).

Interestingly, the statistical analysis supports both intervention models. All parameters are highly significant, and the relevant measures of fit are similar. Finally, both models satisfy the requirement of white noise residuals. Theoreti- 
TABLE 3

The Impact of the URgent Resolution of OCtober 1990 and the ReCognition RATE ON THE NUMBER OF ASYLUM APPLICATIONS

\begin{tabular}{|c|c|c|c|c|c|}
\hline & & $\begin{array}{l}\text { Model 1: Abrupt } \\
\text { Permanent Effect }\end{array}$ & $\begin{array}{l}\text { Model 2: Gradual } \\
\text { Permanent Effect }\end{array}$ & $\begin{array}{l}\text { Model 3: Transfer } \\
\text { Function }\end{array}$ & $\begin{array}{l}\text { Model 4: Transfer and } \\
\text { Intervention Function }\end{array}$ \\
\hline \multicolumn{6}{|c|}{ Input variables: } \\
\hline $\mathrm{C}^{1}$ & & $\begin{array}{c}-583.84 \\
(-2.87)\end{array}$ & $\begin{array}{c}-199.35 \\
(-6.28) \\
0.98\end{array}$ & & $\begin{array}{c}-549.70 \\
(-2.21)\end{array}$ \\
\hline & & & $(102.44)$ & & \\
\hline \multicolumn{6}{|c|}{ Recognition Rate: } \\
\hline \multicolumn{2}{|c|}{ C (shift 7) } & & & $\begin{array}{l}21.05 \\
(2.38)\end{array}$ & $\begin{array}{l}17.15 \\
(1.98)\end{array}$ \\
\hline$\delta_{1}$ & (shift 7) & & & $\begin{array}{c}.70 \\
(6.85)\end{array}$ & $\begin{array}{c}.70 \\
(5.42)\end{array}$ \\
\hline \multicolumn{6}{|c|}{ Noise components: } \\
\hline \multicolumn{6}{|c|}{ ARIMA $(0,1,4)(1,1,0)_{12}$} \\
\hline & $(\operatorname{lag} 3)$ & $\begin{array}{c}-.55 \\
(-6.50)\end{array}$ & & & \\
\hline$\theta_{4}$ & $(\operatorname{lag} 4)$ & $\begin{array}{l}.18 \\
(2.13)\end{array}$ & & & \\
\hline & $(\operatorname{lag} 12)$ & $\begin{array}{c}-.50 \\
(-6.07)\end{array}$ & & & \\
\hline \multicolumn{6}{|c|}{ ARIMA $(2,1,4)(1,1,0)_{12}$} \\
\hline$\phi_{1}$ & (lag 1) & & $\begin{array}{c}-.32 \\
(-3.34)\end{array}$ & & \\
\hline$\phi_{2}$ & (lag 2) & & $\begin{array}{c}-.41 \\
(-4.46)\end{array}$ & & \\
\hline$\theta_{4}$ & (lag 4) & & $\begin{array}{c}.50 \\
(4.95)\end{array}$ & & \\
\hline$\phi_{1,12}$ & (lag 12) & & $\begin{array}{c}-.53 \\
(-6.29)\end{array}$ & & \\
\hline \multicolumn{6}{|c|}{ ARIMA $(2,1,0)(0,1,0)_{12}$} \\
\hline \multicolumn{2}{|c|}{$\phi_{1} \quad(\operatorname{lag} 1)$} & & & $\begin{array}{c}-.25 \\
(-2.63)\end{array}$ & $\begin{array}{c}-.23 \\
(-2.38)\end{array}$ \\
\hline \multicolumn{2}{|c|}{$\phi_{2} \quad(\operatorname{lag} 3)$} & & & $\begin{array}{c}.32 \\
(3.37)\end{array}$ & $\begin{array}{c}.39 \\
(4.07)\end{array}$ \\
\hline$\phi_{1,12}$ & (lag 12) & & & $\begin{array}{c}-.47 \\
(-5.19)\end{array}$ & $\begin{array}{c}-.47 \\
(-5.12)\end{array}$ \\
\hline \multicolumn{6}{|c|}{ Diagnostics: } \\
\hline Corre & lation Estimates & $s \quad|r|<.20$ & $|r|<.32$ & $|r|<.20$ & $|r|<.24$ \\
\hline Autoc & orrelation & $\mathrm{Q}_{\mathrm{df}=21} \quad 23.28$ & $Q_{d f=20} 20.01$ & $Q_{d f=21} \quad 23.91$ & $Q_{\mathrm{df}=21} 22.78$ \\
\hline \multicolumn{3}{|c|}{ Crosscorrelation $\mathrm{Q}_{\mathrm{df}=22}$} & & 17.33 & 15.90 \\
\hline AIC & & 1492.41 & 1475.17 & 1392.76 & 1389.87 \\
\hline SBC & & 1503.00 & 1490.98 & 1405.58 & 1405.26 \\
\hline
\end{tabular}

Note: The results were obtained with SAS-ETS (Maximum Likelihood estimation). t-ratios are in parentheses.

cal considerations are equally of no help to choose among the competing models. However, we can base our choice between the two intervention models on a comparison between the observed and the estimated reduction. A quick glance at Figure 1B suggests that the decline in monthly applications should be somewhere around 3,000. The first model of Table 3 has an estimate of -583.84 for the coefficient $\mathrm{C}$, meaning that the number of applications decreases 
abruptly by 584 . The alternative model has estimated coefficients of -199.35 for $\mathrm{C}$ and .98 for $\mathrm{d}$. After $\mathrm{n}$ periods, the decrease in applications would be $\mathrm{C}\left(1+\delta+\delta^{2}+\ldots+\delta^{\mathrm{n}}\right)$.

Since this would equal asymptotically a decline of 9,968 asylum requests, one could be tempted to conclude that both models are not appropriate. But within a time series framework, not only intervention parameters but also former values of the time series and estimation errors of former periods influence future values. As a further guideline to which intervention model should be preferred, we estimated backforecasts for the number of asylum applications in 1995 by both models. At least for 1995, the more parsimonious model makes far better predictions for the number of asylum applications. The average prediction error for Model 1 is 118.57 applications per month, whereas Model 2 generally overestimates the number of asylum applications by an average of 351.90. It is important to note, however, that the second model has considerable difficulties in correcting inaccurate forecasts because of the two autoregressive parameters on lags one and two. This explains why all predictions of Model 2 for 1995 are far too large. The first model, on the other hand, includes only one autoregressive parameter at lag 12 . Bad forecasts at time $t-1$ and $t-2$ will therefore not influence the prediction of the number of applications at time $t$.

Although Model 1 tends to overestimate the number of asylum requests as well, we conclude from the backforecasting results that the more parsimonious intervention model should be preferred. In short, the impact of the intervention should thus be considered as being abrupt. This finding bears important theoretical implications. When the situation for asylum seekers in Switzerland becomes worse, we observe an immediate switch of a large number of asylum seekers to a more generous host country. The already mentioned development of the German figures sustain this argument. We do not claim that all refugees who flee to another host country are astonishingly well informed about their fate in different Western European nations. Rather, we suspect that organizations that specialize in organizing and coordinating the flight of refugees, and often but not always smuggle them over the border, adapt their strategies very quickly to the changing conditions.

A multivariate time series analysis would allows us to include different push and pull factors as supplementary exogenous variables. As we already mentioned, it does not make sense to us to establish some sort of 'general conflict indicator' on a monthly basis for the estimation of the number of asylum applications aggregated from all sender countries except former Yugoslavia. We therefore omit this push variable in this part of the analysis. 
The first possible cause for the decline in requests has to be denied since our statistical tests did not reveal a significant causal relationship between the economic series and the number of asylum applications. In our investigation period, inflation in Switzerland was relatively constant and therefore has no explanatory power for changes in the number of asylum applications. The fact that we found no significant cross-correlation between unemployment and the number of applications was a bit surprising since the decline in applications and the beginning of an economic recession with a considerable increase in the unemployment rate happened more or less at the same time. The lack of a significant interrelationship between the two series is probably due to the relatively constant unemployment rate in the eighties when the number of requests increased from year to year. ${ }^{6}$ However, these findings could also result from common trends (cointegration) in the series. We therefore employed the Engle-Granger two step technique (Engle and Granger, 1987) to test for cointegration. 7 This means that we first regressed the levels of the number of asylum applications on the levels of the recognition rate, inflation and unemployment and included the dummy of the policy change as suggested by Ostrom and Smith (1992:149). We then tested for a unit root in the residuals of this regression. We added enough lags of differenced regression residuals in order that the residuals of the unit root test be white noise. We obtained an Augmented Dickey-Fuller (ADF) t statistic (Dickey and Fuller, 1979) of -2.21 . The critical value of the .05 significance level for the rejection of the null hypothesis of a unit root can be calculated from MacKinnon's (1991) tables. In our case, this value amounts to -4.19 which is less than the ADF $t$ statistic. This result implies that our different time series do not share a common trend and are accordingly not cointegrated. Hence, we can continue in our ARIMA framework and need not consider alternative methods as error correction models (Durr, 1992; Enders, 1995, chap. 6; Hamilton, 1994, chap. 19; Ostrom and Smith, 1992; Thome, 1997).

The last exogenous time series of Equation (1) is the recognition rate. We estimated first a transfer function model for this variable (Model 3) and included again the intervention of October 1990 (Model 4). The estimation results are presented in Table 3. All coefficients of both Models 3 and 4 are

${ }^{6}$ The crosscorrelations and tentative ARIMA estimation results for the relationship between unemployment and the number of asylum applications are not presented in this article but can be obtained from the authors by request.

${ }^{7}$ Cointegration tests are a means to uncover common trends in several time series. For a discussion of these techniques in a political science context, see, e.g., Ostrom and Smith, 1992 or Durr, 1992. 
statistically significant and otherwise acceptable. The sign of the $\mathrm{C}$ parameter of the recognition rate is positive as expected. Moreover, the time lag of seven periods after which the recognition rate begins to influence the number of applications makes sense from a theoretical point of view. It takes a certain time until the information of changing recognition rates reaches potential asylum seekers - or rather the organizations coordinating their flight. In contrast to the enactment of a regime change, it is not possible to anticipate changing recognition rates. This is not the least a consequence of the fact that the monthly application and recognition figures are usually only published some months after the examination period.

The impact that the recognition rate has on the number of asylum applications is extremely large. The estimated coefficients of Model 3 indicate that a one percent decrease (increase) in the recognition rate at time $t$ causes a decrease (increase) of 21 applications at time $t+7$. Asymptotically, the effect of a one percent change in the recognition rate on the number of applications is about 70. It is important to note, however, that a 10 percent lower recognition rate would not necessarily mean a decrease of 700 applications per month in the long run since future applications strongly depend upon present requests. This suggests at least the three autoregressive parameters. This result is seemingly at odds with the figures depicted in Table 1 where years with a high number of applications correspond with low recognition rates.

There are three factors that solve this alleged puzzle. First, the statistical analysis covers the period 1986-1995 only, due to missing data on monthly level for prior periods. The extremely high admission ratios of the first half of the 1980s are, accordingly, not part of the estimation. Second, the results are not based on yearly, but rather monthly, data. Third, and most importantly, our findings are the result of a dynamic estimation rather than a comparative static comparison. The impact of changing recognition rates on the number of requests is not an immediate one, but starts to take place with a lag of seven months. Our findings imply that state authorities can use the recognition rate as a highly questionable steering tool to influence future applications.

In the synthesizing Model 4, the urgent resolution has about the same effect as in Model 1 . The other parameter estimates do not substantially differ from those of Model 3. We suspect that the results will become more clear when we disaggregate the time series and look at the development in the applications from the main sender countries. This perspective will not only enable us to determine the effects of legal deterrence measures and recognition rates for selected countries, but also allow us to formally include the con- 


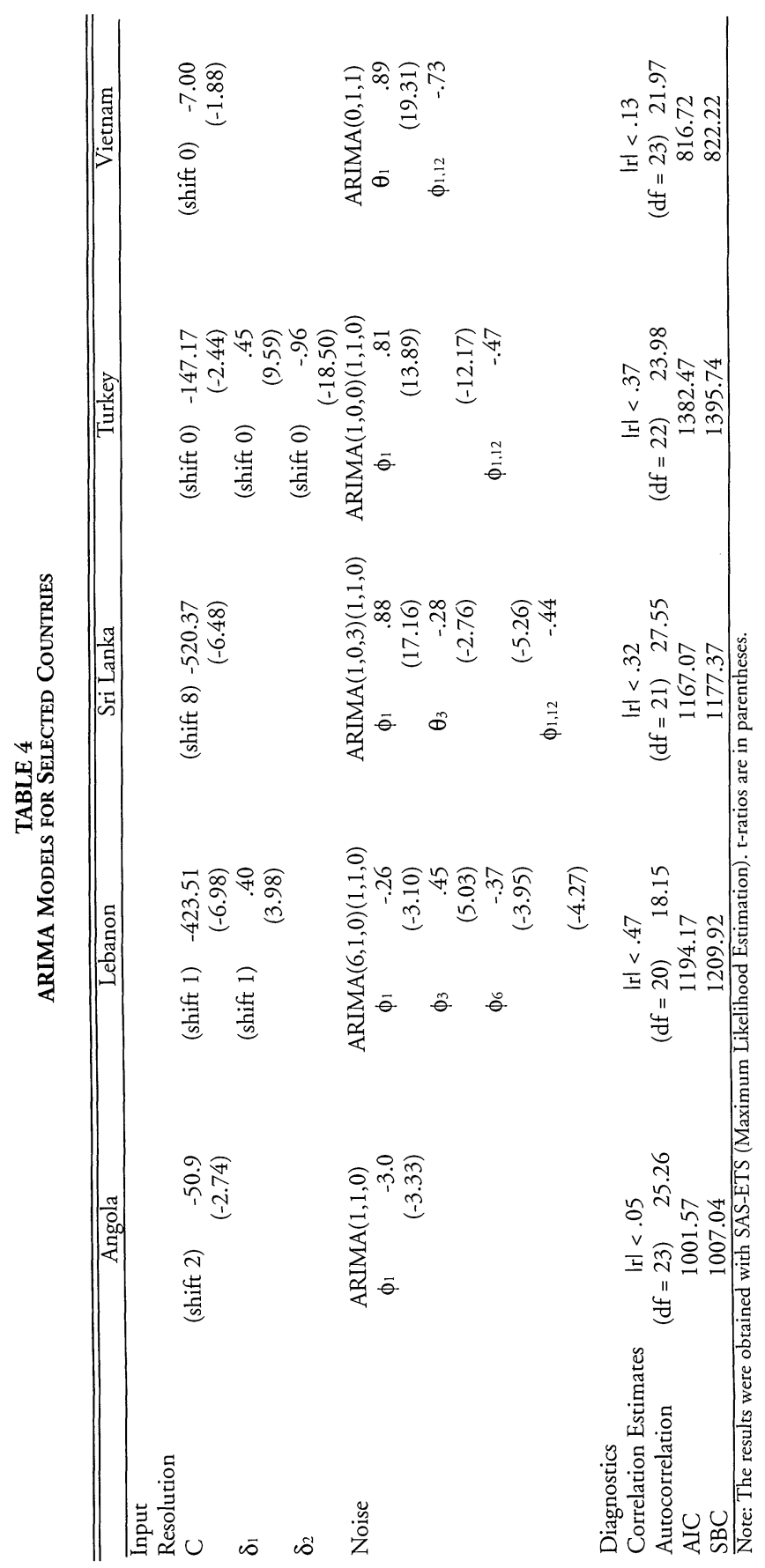


cept of push factors in the analysis. Table 3 summarizes the results of this step of analysis.

The most striking result depicted in Table 4 is the fact that country-specific recognition rates do not bear a significant impact on the number of asylum applications in any of the five selected countries. Conversely, the intervention of October 1990 decreased the number of requests in all five countries. Moreover, there are substantial differences in the types of effects for different countries. For Angola, Lebanon and Vietnam, the effect occurred abruptly, leading to a dramatic decline in the number of applications from Lebanon and a rather strong decrease in the number of requests from Angola. The effect on Vietnamese applications, by contrast, is rather modest and not significant at the .05 level. It is important to note that the effect starts to take place only after a lag of one month in Lebanon and after two months in Angola. This indicates that it takes a certain time until the information about the new legal framework in Switzerland reaches potential sender countries. Once the new procedures are known, a reaction follows immediately. The two main sender countries during the 1980s, namely Sri Lanka and Turkey, react gradually but very differently to the intervention. In Sri Lanka, the effect is very large, but the time series of applications begins to decrease only after a lag of eight months. Conversely, the intervention affects potential asylum seekers from Turkey immediately. However, as the plot in Figure 2 indicates, the downward process is rather complicated and follows a second order intervention function (see the Appendix). Finally, the autoregressive noise parameters for all countries but Vietnam indicate that the time series are highly dependent on their past values. This is in line with the common sense argument that refugees tend to try to reach countries where already quite a large number of compatriots live. Vietnam's single noise parameter is a moving average term at lag 1 and thus suggests a random development of the series of applications. This seems consistent with the plot in Figure 2.

If we consider the global recognition rate instead of country-specific admission ratios, the results remain more or less the same. The global recognition rate influences the number of asylum applications only in the case of Angola. But the magnitude of this impact is rather modest. With a lag of ten months, a one percent increase (decrease) in the global recognition rate leads to an increase (decrease) of 1.33 applications. As an additional step, we estimated the impact of economic variables as push factors for Turkey and Sri Lanka. Whereas inflation in Sri Lanka and unemployment in Turkey do not affect the number of asylum requests, inflation in Turkey seems to have quite 
a large influence. The estimated coefficients for inflation are $\mathrm{C}=5.21$ and $\delta_{1}=.86$ with a lag of 4 months, but it should be noted that the t-value for the $\mathrm{C}$ coefficient only amounts to 1.93 . Asymptotically, a one percent increase (decrease) in the Turkish inflation rate causes an increase (decrease) of 37 applications. Since inflation in Turkey varied considerably (between $30 \%$ and $130 \%$ ) during our investigation period, its impact has to be considered important. Another interesting point is that the inclusion of the inflation rate transforms the impact of the legal intervention. Without this push factor, only a rather complicated second order intervention function is able to account for the spike in the number of applications after the intervention. If we include the inflation rate, the intervention can be modeled as an abrupt effect after a lag of five months. In this case, the federal resolution leads to a decrease of 487 applications.

The country-specific time series analyses reveal the strong impact of the legal intervention of October 1990. In all countries but Vietnam, the time series analysis results show that the intervention significantly decreased the number of applications. Conversely and surprisingly, we could not find a significant relationship between both country-specific and global recognition rates and the number of asylum requests in country-based estimations. In order to find an explanation for this counterintuitive result, we generated a time series which contains the number of asylum applications from all other countries. In a multivariate ARIMA model with autoregressive parameters at lags 1, 3 and 12, we found that the urgent resolution leads to an abrupt decrease of 683 applications with a lag of one month, whereas the global recognition rate also showed a significant impact. A one percent increase (decrease) in the global recognition rate causes an increase (decrease) of 8.44 applications. Since our dependent variable is the number of monthly applications, all these effects are important.

\section{CONCLUSION}

Although they are governed by parties of different orientation and have undergone economic crises at different times and of different magnitudes, most states have abandoned the liberal refugee regime of the post World War II era. Departing from the well known dual concept of push and pull factors for migration, our statistically-based case study has focused on the impact of deterrence measures on the number of asylum applications in Switzerland.

The time series analyses reveal that the dichotomous manner in which the debate over the role of the state in migration matters is led is largely mis- 
leading. While one school of thought believes that states are more or less impotent in this domain, other researchers believe that the governments of the industrialized world are the real problem. In their view, states are increasingly adopting measures that successfully deter potential refugees from applying for asylum. Our statistical results clearly show that a relatively small industrialized country like Switzerland can influence the inflow of refugees, however not all the time and with all policies. Deterrence measures are unsuccessful if the push factors in a region nearby to the receiving state reach a critical level. During the period under investigation, the most significant example in this vein were the civil wars in the former Yugoslavia. The tragedy in Kosovo caused by Serb nationalist leader Slobodan Milosevic led to another inflow of refugees that was, at least in the beginning, beyond the administrative capacities of some states. To deal with such humanitarian disasters, host countries increasingly move towards a policy of temporary protection. This means that asylum seekers are sent back to their country of origin as soon as the situation there has calmed down.

The analysis also demonstrates that governments have been successfully controlling the number of asylum applications through their manipulation of the relative number of recognized refugees. The interrelationship between recognition rates and the number of asylum seekers is objectionable insofar as it contradicts the right of an individual to receive a fair treatment of an asylum application irrespective of the general asylum situation.

An important point beyond the scope of this article is the question of whether the postwar regime of the Geneva Convention is still an appropriate device for the needs of refugees and receiving states caused by the problems of today. Are there grounds that should be relevant for granting asylum other than "a well-founded fear of being persecuted for reasons of race, religion, nationality, membership in a particular social group or political opinion" such as violence, famine, gender, sexual orientation, etc.? The fact that an overwhelming majority of asylum applications are turned down but a large number of the persons who were not granted refugee status are allowed to stay in the host country for a limited time on humanitarian grounds points in this direction. In June 1999, the Swiss population accepted a referendum on a new asylum law by a majority of 70 percent. One of the newly adopted provisions contains the protection for refugees fleeing from violence and war. It enables the government to decide in a general fashion how many persons fleeing from a war will be given the right of temporary protection. But this provision, as generous as it may sound at first sight, has one major aim - it 
was designed to prevent such refugees from going through the costly asylum procedure where each case has to be treated individually. The introduction of this new policy demonstrates once again that the Swiss authorities verbally promote new humanitarian mechanisms, but are not willing to break decisively with the old regime. This article has demonstrated, with regard to future legislative measures, that the tradeoff between international commitments and unilateral measures is one of the crucial conflicts in the asylum policy of Western European states.

\section{APPENDIX:}

\section{Specification of the Baseline Model}

This appendix is intended to specify the general notation of Equation 2 in the main text for the estimated models. To this end, we first discuss the principal steps of ARIMA modeling. This enables us later to formulate the noise components of the four models, i.e., the term $\mathrm{N}_{t}$ on the right hand side of Equation (2) of the main text. Second, without entering into the details of the intervention and transfer function methodology, we want to introduce the functional forms $f\left(I_{t}\right)$.

As noted in the main text, ARIMA models are based on the assumption that any time series can be expressed as a stochastic process. The realizations in different time points of such a process, i.e., the observed values of the time series under consideration, must meet certain conditions. The first requirement for modeling time series in the ARIMA framework is that the series must be stationary. The series under consideration (in our case the number of asylum applications) $\mathrm{Y}_{\mathrm{t}}$ is stationary if:

(i) $E\left|Y_{t}\right|^{2}<\infty$

(ii) $\mathrm{E}\left(\mathrm{Y}_{\mathrm{t}}\right)=\mathrm{m}$

(iii) $\mathrm{E}\left[\left(\mathrm{Y}_{\mathrm{t}}-\mathrm{E}\left(\mathrm{Y}_{\mathrm{t}}\right)\right)\left(\mathrm{Y}_{\mathrm{s}}-\mathrm{E}\left(\mathrm{Y}_{\mathrm{s}}\right)\right)\right]=\operatorname{Cov}\left(\mathrm{Y}_{\mathrm{t}}, \mathrm{Y}_{\mathrm{s}}\right)=\gamma_{\mathrm{y}}(\mathrm{t}, \mathrm{s})=\gamma_{\mathrm{y}}(\mathrm{t}+\mathrm{s}+\mathrm{r}) \nabla \mathrm{r}, \mathrm{t}, \mathrm{s}$

The three conditions signify that the variance of $Y_{t}$ has to be finite, the mean constant, and the covariance between two realizations with equal time intervals must not vary over time (see Hamilton, 1994:45-46). Unfortunately, most time series in the social sciences are nonstationary. Therefore, the initial series $Y_{t}$ has to be transformed into a stationary series $Y_{t}^{*}$. If condition (iii) in Equation (A1) is violated, then transformations that take the natural $\log$ or the square root of $Y_{t}$ will generally transform into a stationary series $Y_{t}{ }^{*}$. 
If $Y_{t}$ has not constant mean, only differencing the series $Y_{t}$ might guarantee the emergence of a stationary series $Y_{t}^{*}$. Time series analysts inspect the autocorrelation function (ACF) to determine the level of differencing needed. ${ }^{8}$ Usually, taking the first differences will suffice to obtain a stationary series. A $\mathrm{d}$ times differenced time series is referred as to an integrated stochastic process of order $\mathrm{d}$. A more sophisticated means for uncovering the necessary degree of differencing is to test for a unit root. ${ }^{9}$ The ACF and PACF (partial autocorrelation function) are then used to identify the necessary autoregressive and moving average parameters to specify the data-generating process. The general ARIMA representation for a stationary series is:

$\mathrm{Y}_{\mathrm{t}}^{*}-\phi_{1} \mathrm{Y}_{\mathrm{t}-1}^{*}-\phi_{2} \mathrm{Y}_{\mathrm{t}-2}^{*}-\cdots-\phi_{\mathrm{p}} \mathrm{Y}_{\mathrm{t}-\mathrm{p}}^{*}=\mathrm{C}+\mathrm{a}_{\mathrm{t}}+\theta_{1} \mathrm{a}_{\mathrm{t}-1}+\theta_{2} \mathrm{a}_{\mathrm{t}-2}++\ldots+\theta_{\mathrm{q}} \mathrm{a}_{\mathrm{t}-\mathrm{q}}$
with $\mathrm{a}_{\mathrm{t}} \sim \mathrm{WN}\left(0, \sigma^{2}\right)$

Note that not all autoregressive parameters on the left-hand side and not all of the moving average parameters on the right hand side have to be different from zero. Further, the constant term $\mathrm{C}$ should be omitted if the series has been previously differenced. ${ }^{10}$ The white noise distribution of the moving average parameters of Equation (A2) requires zero mean, variance of $\sigma^{2}$ and zero covariance between all realizations of different time points. Formally, this implies:

(i) $\mathrm{E}\left(\mathrm{a}_{\mathrm{t}}\right)=0$

(ii) $\gamma_{a}(t, s)= \begin{cases}\sigma^{2} & t=s \\ 0 & t \neq s\end{cases}$

By introducing the backshift operators $\Phi_{\mathrm{p}}\left(1-\phi_{1} \mathrm{~B}-\ldots-\phi_{\mathrm{p}} \mathrm{B}^{\mathrm{P}}\right)$ and $\Phi_{\mathrm{q}}(\mathrm{B})=$ $\left(1-\phi_{1} \mathrm{~B}+\ldots+\phi_{\mathrm{q}} \mathrm{B}^{\mathrm{q}}\right)$ representing an autoregressive process of order $\mathrm{p}$ and $\mathrm{a}$ moving average process of order q, respectively, Equation (A2) can be written

${ }^{8}$ The stationarity of a series Yt imples that $y y(t, s)=y y(t-s, 0)$. Therefore, the covariance function of a stationary process can be defined as $y_{y}(h)=y_{y}(h, 0)=\operatorname{Cov}\left(Y_{t+h}, Y_{t}\right)$ where $h$ denotes the lag. The ACF $\rho_{y}(\mathrm{~h})$ is determined by $\rho_{y}(\mathrm{~h})=\gamma_{\mathrm{y}}(\mathrm{h}) / \gamma_{\mathrm{y}}(0)=\operatorname{Corr}\left(\mathrm{Y}_{\mathrm{t}+\mathrm{h}} \mathrm{Y}_{\mathrm{t}}\right)$.

${ }^{9}$ The most common test in this regard is the Dickey-Fuller test (Fuller, 1976; Fuller and Dickey, 1979). We conducted unit root tests on each of our time series. The transformed series which we finally used for estimation do not contain a unit root (i.e., are stationary) on the .01 significance level. Detailed results can be obtained from the authors upon request. Since the focus of this article is empirical rather than methodological, we omit the formal notation of the estimated equations. A good representation can be found in Durr, 1992 or Ostrom and Smith, 1992; for more details see Hamilton, 1994; chaps. 15-18 and Enders, 1995, chap. 4. ${ }^{10}$ For simplicity, we omit the constant in further equations. 
compactly as

$\Phi_{\mathrm{p}}(\mathrm{B}) \mathrm{Y}_{\mathrm{t}}^{*}=\Phi_{\mathrm{p}}(\mathrm{B}) \mathrm{a}_{\mathrm{t}}$ or $\mathrm{Y}_{\mathrm{t}}^{*}=\frac{\Phi_{\mathrm{p}}(\mathrm{B})}{\Phi_{\mathrm{q}}(\mathrm{B})} \mathrm{a}_{\mathrm{t}}$

The time series, whether transformed or not, is called ARIMA(p,d,q), where $\mathrm{p}$ denotes the highest order nonzero autoregressive parameter, $d$ the level of differencing, and $\mathrm{q}$ stands for the highest order nonzero moving average parameter.

Many time series, especially in economics but also in the other social sciences, are based on quarterly or monthly data which may include some seasonal variation. In some cases, seasonal differencing may be needed to transform the initial series into a stationary process. ${ }^{11}$ To obtain the full data-generating process might moreover necessitate seasonal autoregressive and/or moving average parameters. The following extension of Equation (A3) captures seasonal effects

$Y_{t}^{*} \Phi_{p}(B) \Phi_{p}\left(B^{s}\right)=\Theta_{q}(B) \Theta_{Q}\left(B^{s}\right) a_{t}$ or $Y_{t}^{*}=\frac{\Theta_{q}(B) \Theta_{Q}\left(B^{s}\right)}{\Phi_{p}(B) \Phi_{p}\left(B^{s}\right)} a_{t}$

The seasonal operators are conventionally subscripted with capital letters, and the process including seasonality is referred to as ARIMA(p,d,q)(P,D,Q)s. Note that the relationship between seasonal and nonseasonal operators of the same kind is multiplicative rather than additive. Additively included parameters would be estimated on a regular but not on a seasonal level.

The next step after the tentative identification of an ARIMA model is diagnostic checking, where the model must satisfy the following criteria:

1) All estimated coefficients have to be statistically significant. The relevant $\mathrm{t}$-statistic can be interpreted like in conventional OLS regressions.

2) The estimated coefficients must lie inside the bounds of invertibility and stationarity. The latter concept requires that the absolute value of the sum of all coefficients in each autoregressive operator is less than one. The invertibility condition is satisfied if the absolute value of the sum of all coefficients in each moving average operator is less than one.

${ }^{11}$ Our time series of the number of asylum applications remained nonstationary after taking first differences. We therefore differenced the series a second time on the seasonal level. Note that regular and seasonal differencing leads to a rather difficult series to interpret: $Y_{t}^{*}=$ $\left(Y_{t}-Y_{t-1}\right)-\left(Y_{t-12}-Y_{t-13}\right)=Y_{t}-Y_{t-1}-Y_{t-12}+Y_{t-13}=(1-B)\left(1-B^{12}\right)=Y_{t}$ 
3) The residuals of the estimated model must not be different from white noise. The Q-statistic is a portmanteau test for the nullhypothesis of autocorrelated residuals. ${ }^{12}$ In addition to an acceptable value for $\mathrm{Q}$ at approximately 24 lags, the ACF and PACF of the residuals must not have significant spikes at any lag.

If the tentative model does not withstand one of these tests, the analyst must look for a different model. Theoretically, the same time series can be modeled by different ARIMA models that all satisfy the requirements of diagnostic checking. More parsimonious models should generally be preferred to ones that contain many seasonal or nonseasonal AR and MA parameters. Another indicator for the choice of the most appropriate model are measures of fit such as the Akaike Information Criterion (AIC) or the Schwartz Bayes Information Criterion (SBC). ${ }^{13}$

Equation (A5) is the general representation of the noise component of an intervention impact model. In order to formulate our estimated models, we have to extend Equation (A5) by the functional form of $f\left(I_{t}\right)$. The latter depends, in case of a step input intervention, i.e., a permanent impact, on whether the effect occurs abruptly or gradually. In our first model, we estimated an abrupt permanent effect of the intervention on the number of asylum applications. This is the simplest case for an intervention and is referred to as a zero order intervention function. In that case, the functional form of the intervention is $\mathrm{f}\left(\mathrm{I}_{\mathrm{t}}\right)=\mathrm{CI}_{\mathrm{t}}$. The noise component in our first model contains two moving average parameters at lag 3 and 4 and one autoregressive parameter at lag 12. The full technical notation for Model 1 is thus:

$Y_{t}^{*}=C_{t} 1+\frac{1+\theta_{3} B^{3}+\theta_{4} B^{4}}{1-\phi_{1,12} B^{12}} a_{t} \quad$ with $\quad Y_{t}=\frac{Y_{t}^{*}}{(1-B)\left(1-B^{12}\right)}$

${ }^{12}$ All software packages that are able to estimate ARIMA models present the Q-statistic in standard output. The statistic is calculated as

$$
\mathrm{Q}=\mathrm{T}_{\mathrm{i}=1}^{\mathrm{h}}\left(\rho_{\mathrm{y}}(\mathrm{h})\right)^{2}
$$

T stands for the number of observations and $h$ denotes the lag where $Q$ is evaluated. $Q$ is chisquare distributed with $\mathrm{h}-\mathrm{p}-\mathrm{q}-\mathrm{P}-\mathrm{Q}$ degrees of freedom.

${ }^{13}$ The general rule is that the lower values these information criterions take the better the fit of a model. Most computer packages calculate AIC and SBC. The two criterions are defined as follows: $\mathrm{AIC}:=\log \left(\mathrm{s}^{2}\right)+2(\mathrm{p}+\mathrm{q}+\mathrm{P}+\mathrm{Q}) / \mathrm{T}, \mathrm{BC}:=\log \left(\mathrm{s}^{2}\right)+\log (\mathrm{T})(\mathrm{p}+\mathrm{q}+\mathrm{P}+\mathrm{Q}) / \mathrm{T}$ where $s$ denotes the estimated standard error of the model. Note that both AIC and SBC penalize those analysts who add parameters to their model. Therefore, the comparison of competing models according to AIC and SBC should be preferred to simpler measurements of fit as, for example, the root mean squared error. 
A gradual permanent effect is modeled by a first order intervention function. Here, $f\left(I_{t}\right)=C_{t} /(1-\delta B)$. The parameter $\delta$, which must lie between -1 and +1 , indicates the speed at which a gradual permanent effect occurs. A negative $\delta$ implies that the time series reaches its new level after the intervention in an oscillating form. A positive value for $\delta$ stands for a conventional gradual effect, namely a smooth development in an upward or downward direction. The closer $\delta$ comes to zero, the faster the effect develops its full magnitude; i.e., if $\delta=0, \mathrm{CI}_{\mathrm{t}} /(1-\delta \mathrm{B})$ reduces to $\mathrm{CI}_{\mathrm{t}}$. With the noise component presented in Table 3, Model 2 is:

$$
Y_{t}^{*}=\frac{C}{1-\delta B} I_{t}+\frac{1+\theta_{4} B^{4}}{\left(1-\phi_{1} B-\phi_{2} B^{2}\right)\left(1-\phi_{1,12} B^{12}\right)} \text { at with } Y_{t}=\frac{Y_{t}^{*}}{(1-B)\left(1-B^{12}\right)}
$$

The formal notation of transfer functions is less obvious. We therefore omit the general form but present below the notation of Model 3 with the recognition rate as the exogenous time series $\mathrm{X}_{\mathrm{t}}^{*}$ :

$Y_{t}^{*}=\frac{C}{1-\delta B} B^{7} X_{t}^{*}+\frac{a_{t}}{\left(1-\phi_{1} B-\phi_{2} B^{2}\right)\left(1-\phi_{1,12} B^{12}\right)}$

with $Y_{t}=\frac{Y_{t}^{*}}{(1-B)\left(1-B^{12}\right)}$ and $X_{t}=\frac{X_{t}^{*}}{(1-B)\left(1-B^{12}\right)}$

The same diagnostic checking as for univariate ARIMA models applies to intervention models. Diagnostic checking of transfer functions contains one more item. The crosscorrelations between the residuals of the estimated model and the exogenous series must not be statistically different from zero. The same portmanteau test (Q-statistic) as for testing the nullhypothesis of autocorrelated residuals can be used here. The intervention and transfer function models can be easily combined in order to obtain the representation of Model 4.

The estimation results of the impact of the legal intervention on Turkish asylum applications depicted in Table 4 refer to a second order intervention function. Since the nature of such an impact is by no means obvious, we want to briefly outline this model. The full technical notation of the Turkish model is:

$Y_{t}^{*}=\frac{C}{1-\delta_{1} B-\delta_{2} B^{2}} I_{t}+\frac{a_{t}}{\left(1-\phi_{1} B\right)\left(1-\phi_{1,12} B^{12}\right)}$ with $Y_{t}=\frac{Y_{t}^{*}}{(1-B)\left(1-B^{12}\right)}$

We want here to focus only on the intervention component, i.e., the first 
term on the right hand side of Equation (9), and omit therefore the noise component in the next equations. The intervention component can be written as $1-\delta_{1} \mathrm{~B}-\delta_{2} \mathrm{~B}^{2}=\mathrm{CI}_{\mathrm{t}}$ or equivalently $\mathrm{Y}_{\mathrm{t}}^{*}=\delta_{1} \mathrm{Y}_{\mathrm{t}-1}+\delta_{2} \mathrm{Y}_{\mathrm{t}-2}+\mathrm{CI}_{\mathrm{t}}$

Prior to the intervention, when $I_{t}=0, Y_{t}^{*}=0$. At the first period after the intervention, $i+1$, however, the step function changes from zero to one, and without considering the noise parameters, the value of $Y_{t+1}^{*}$ is expected to be:

$\mathrm{Y}_{\mathrm{i}+1}^{*}=\delta_{1} \mathrm{Y}_{\mathrm{i}}+\delta_{2} \mathrm{Y}_{\mathrm{i}-1}^{*}+\mathrm{CI}_{\mathrm{i}+1}=\delta_{1}(0)+\delta_{2}(0)=\mathrm{C}(1)=\mathrm{C}$

and one period later

$Y_{i+2}^{*}=\delta_{1} Y_{i+1}+\delta_{2} Y_{i}^{*}+C_{i+2}=\delta_{1}(C)+\delta_{2}(0)=C(1)=\delta_{1} C+C$,

in the next period

$\mathrm{Y}_{\mathrm{i}+3}^{*}=\delta_{1} \mathrm{Y}_{\mathrm{i}+2}+\delta_{2} \mathrm{Y}_{\mathrm{i}+1}^{*}+\mathrm{CI}_{\mathrm{i}+3}=\delta_{1}\left(\delta_{1} \mathrm{C}+\mathrm{C}\right)+\delta_{2}(\mathrm{C})+\mathrm{C}(1)$

$=\delta_{1}^{2} \mathrm{C}+\delta_{1} \mathrm{C}+\delta_{2} \mathrm{C}+\mathrm{C}$,

and so forth. The combination of the values of the two $\delta$ parameters in the Turkish model can account for the spike in the time series of applications after the intervention and the gradual decrease of applications that follows.

TABLE 1

Number of Asylum Applications from Main Sender Countries

\begin{tabular}{lcccccccc}
\hline \hline & & & & & & & & Total less \\
& Angola & Lebanon & Sri Lanka & Turkey & Vietnam & Yugoslavia & Total & Yugoslavia \\
\hline $1986: 01$ & 15 & 9 & 35 & 292 & 16 & 33 & 548 & 515 \\
$1986: 02$ & 4 & 6 & 71 & 145 & 15 & 4 & 369 & 365 \\
$1986: 03$ & 14 & 10 & 62 & 133 & 13 & 6 & 370 & 364 \\
$1986: 04$ & 9 & 14 & 34 & 155 & 14 & 2 & 411 & 409 \\
$1986: 05$ & 7 & 15 & 32 & 146 & 10 & 19 & 377 & 358 \\
$1986: 06$ & 14 & 15 & 34 & 236 & 23 & 9 & 477 & 468 \\
$1986: 07$ & 5 & 41 & 22 & 392 & 19 & 8 & 728 & 720 \\
$1986: 08$ & 5 & 18 & 46 & 512 & 12 & 9 & 896 & 887 \\
$1986: 09$ & 19 & 7 & 39 & 713 & 14 & 10 & 1194 & 1184 \\
$1986: 10$ & 17 & 4 & 57 & 691 & 27 & 6 & 1245 & 1239 \\
$1986: 11$ & 6 & 6 & 65 & 355 & 7 & 9 & 1026 & 1017 \\
$1986: 12$ & 10 & 0 & 102 & 310 & 5 & 4 & 905 & 901 \\
$1987: 01$ & 11 & 2 & 178 & 306 & 10 & 10 & 850 & 840 \\
$1987: 02$ & 14 & 10 & 115 & 278 & 21 & 3 & 730 & 727 \\
$1987: 03$ & 19 & 2 & 126 & 459 & 19 & 6 & 980 & 974 \\
$1987: 04$ & 14 & 7 & 82 & 480 & 11 & 14 & 814 & 800 \\
$1987: 05$ & 12 & 7 & 73 & 342 & 20 & 19 & 659 & 640 \\
$1987: 06$ & 5 & 13 & 58 & 287 & 3 & 10 & 569 & 559 \\
$1987: 07$ & 13 & 23 & 112 & 324 & 8 & 14 & 693 & 679
\end{tabular}


TABLE 1 (CONTINUED)

Number of AsYlum APPlications from Main SENDER Countries

\begin{tabular}{|c|c|c|c|c|c|c|c|c|}
\hline & Angola & Lebanon & Sri Lanka & Turkey & Vietnam & Yugoslavia & ia Total & $\begin{array}{c}\text { Total less } \\
\text { Yugoslavia }\end{array}$ \\
\hline & \multicolumn{2}{|c|}{$1987: 08$} & 12 & 39 & 45 & 400 & 7 & 14 \\
\hline 823 & 809 & & 1987:09 & 24 & 162 & 29 & 589 & 14 \\
\hline 4 & 1057 & 1053 & & $1987: 10$ & 29 & 71 & 26 & 1010 \\
\hline 26 & 16 & 1619 & 1603 & & 1987:11 & 22 & 21 & 13 \\
\hline 849 & 16 & 4 & 1196 & 1192 & & $987: 12$ & 22 & 18 \\
\hline 38 & 501 & 2 & 16 & 923 & 907 & & 988:01 & 38 \\
\hline 33 & 53 & 1185 & 10 & 12 & 1610 & 1598 & & 1988:02 \\
\hline 17 & 20 & 16 & 442 & 15 & 34 & 789 & 755 & \\
\hline 1988:03 & 8 & 9 & 23 & 264 & 4 & 31 & 480 & 449 \\
\hline 1988:04 & 23 & 7 & 40 & 412 & 13 & 37 & 693 & 656 \\
\hline 1988:05 & 9 & 34 & 37 & 659 & 20 & 36 & 1019 & 983 \\
\hline $1988: 06$ & 21 & 17 & 81 & 813 & 6 & 53 & 1277 & 1224 \\
\hline 1988:07 & 48 & 24 & 87 & 884 & 15 & 34 & 1375 & 1341 \\
\hline 1988:08 & 27 & 54 & 82 & 1080 & 21 & 66 & 1780 & 1714 \\
\hline 1988:09 & 32 & 50 & 124 & 1414 & 2 & 87 & 2083 & 1996 \\
\hline $1988: 10$ & 35 & 104 & 243 & 1379 & 13 & 107 & 2321 & 2214 \\
\hline 1988:11 & 31 & 87 & 331 & 688 & 6 & 185 & 1736 & 1551 \\
\hline 1988:12 & 33 & 94 & 402 & 469 & 4 & 137 & 1563 & 1426 \\
\hline 1989:01 & 27 & 85 & 506 & 494 & 17 & 128 & 1615 & 1487 \\
\hline 1989:02 & 37 & 21 & 337 & 450 & 4 & 92 & 1176 & 1084 \\
\hline 1989:03 & 33 & 45 & 466 & 885 & 7 & 100 & 1931 & 1831 \\
\hline 1989:04 & 28 & 37 & 374 & 632 & 14 & 68 & 1469 & 1401 \\
\hline 1989:05 & 18 & 65 & 360 & 584 & 1 & 88 & 1394 & 1306 \\
\hline $1989: 06$ & 51 & 119 & 500 & 743 & 42 & 77 & 1905 & 1828 \\
\hline 1989:07 & 44 & 202 & 445 & 802 & 12 & 66 & 2014 & 1948 \\
\hline 1989:08 & 27 & 327 & 512 & 914 & 10 & 84 & 2368 & 2284 \\
\hline 1989:09 & 56 & 425 & 354 & 806 & 4 & 130 & 2310 & 2180 \\
\hline $1989: 10$ & 67 & 666 & 468 & 1065 & 13 & 168 & 3155 & 2987 \\
\hline 1989:11 & 95 & 327 & 256 & 1193 & 15 & 212 & 2922 & 2710 \\
\hline 1989:12 & 92 & 166 & 228 & 819 & 29 & 152 & 2166 & 2014 \\
\hline 1990:01 & 136 & 459 & 356 & 1102 & 4 & 219 & 2950 & 2731 \\
\hline 1990:02 & 71 & 166 & 403 & 495 & 27 & 276 & 1968 & 1692 \\
\hline 1990:03 & 86 & 218 & 332 & 393 & 16 & 307 & 1970 & 1663 \\
\hline 1990:04 & 60 & 224 & 295 & 415 & 15 & 220 & 1772 & 1552 \\
\hline 1990:05 & 79 & 318 & 326 & 408 & 3 & 170 & 2014 & 1844 \\
\hline 1990:06 & 72 & 410 & 274 & 581 & 11 & 171 & 2266 & 2095 \\
\hline 1990:07 & 62 & 428 & 465 & 554 & 6 & 310 & 2934 & 2624 \\
\hline 1990:08 & 64 & 795 & 480 & 804 & 8 & 423 & 4019 & 3596 \\
\hline 1990:09 & 76 & 686 & 244 & 713 & 31 & 719 & 3589 & 2870 \\
\hline $1990: 10$ & 169 & 973 & 476 & 713 & 6 & 1099 & 5011 & 3912 \\
\hline 1990:11 & 161 & 552 & 632 & 550 & 7 & 965 & 4263 & 3298 \\
\hline 1990:12 & 101 & 268 & 486 & 473 & 5 & 792 & 3080 & 2288 \\
\hline 1991:01 & 142 & 369 & 827 & 739 & 7 & 1193 & 4786 & 3593 \\
\hline 1991:02 & 108 & 202 & 922 & 624 & 5 & 915 & 4032 & 3117 \\
\hline 1991:03 & 73 & 145 & 1040 & 362 & 8 & 1075 & 3703 & 2628 \\
\hline 1991:04 & 133 & 175 & 951 & 370 & 10 & 823 & 3388 & 2565 \\
\hline 1991:05 & 83 & 77 & 1057 & 364 & 2 & 793 & 3387 & 2594 \\
\hline 1991:06 & 63 & 70 & 571 & 304 & 20 & 679 & 2871 & 2192 \\
\hline 1991:07 & 43 & 93 & 448 & 320 & 8 & 638 & 2810 & 2172 \\
\hline 1991:08 & 28 & 63 & 462 & 306 & 9 & 1373 & 3553 & 2180 \\
\hline 1991:09 & 41 & 55 & 184 & 201 & 1 & 1476 & 3042 & 1566 \\
\hline
\end{tabular}


TABLE 1 (CoNTINUED)

Number of ASYlum APPLICATIONS FROM MAIN SENDER COUNTRIES

\begin{tabular}{|c|c|c|c|c|c|c|c|c|}
\hline & Angola & Lebanon & Sri Lanka & Turkey & Vietnam & Yugoslavia & Total & $\begin{array}{c}\text { Total less } \\
\text { Yugoslavia }\end{array}$ \\
\hline 1991:10 & 35 & 54 & 328 & 256 & 4 & 1898 & 3749 & 1851 \\
\hline 1991:11 & 33 & 32 & 333 & 256 & 3 & 1745 & 3366 & 1621 \\
\hline 1991:12 & 14 & 22 & 220 & 209 & 9 & 1590 & 2945 & 1355 \\
\hline 1992:01 & 17 & 47 & 390 & 304 & 2 & 2196 & 3946 & 1750 \\
\hline 1992:02 & 28 & 39 & 277 & 186 & 2 & 348 & 1467 & 1119 \\
\hline $1992: 03$ & 12 & 41 & 227 & 238 & 8 & 326 & 1493 & 1167 \\
\hline 1992:04 & 3 & 21 & 139 & 147 & 7 & 226 & 948 & 722 \\
\hline 1992:05 & 5 & 25 & 147 & 142 & 18 & 292 & 1094 & 802 \\
\hline $1992: 06$ & 11 & 28 & 207 & 96 & 7 & 253 & 1031 & 778 \\
\hline 1992:07 & 5 & 35 & 316 & 115 & 1 & 294 & 1251 & 957 \\
\hline 1992:08 & 5 & 42 & 356 & 156 & 2 & 465 & 1551 & 1086 \\
\hline 1992:09 & 7 & 30 & 226 & 130 & 12 & 394 & 1243 & 849 \\
\hline $1992: 10$ & 6 & 52 & 204 & 102 & 2 & 608 & 1535 & 927 \\
\hline 1992:11 & 2 & 50 & 190 & 177 & 14 & 572 & 1528 & 956 \\
\hline 1992:12 & 4 & 24 & 112 & 86 & 1 & 291 & 1047 & 756 \\
\hline 1993:01 & 20 & 57 & 282 & 48 & 0 & 899 & 2461 & 1562 \\
\hline $1993: 02$ & 25 & 42 & 151 & 80 & 3 & 1121 & 2217 & 1095 \\
\hline 1993:03 & 21 & 53 & 109 & 80 & 2 & 983 & 1942 & 933 \\
\hline 1993:04 & 27 & 34 & 174 & 101 & 16 & 918 & 2110 & 1167 \\
\hline 1993:05 & 14 & 17 & 88 & 80 & 19 & 864 & 1829 & 905 \\
\hline 1993:06 & 39 & 29 & 120 & 114 & 22 & 690 & 1727 & 1018 \\
\hline 1993:07 & 65 & 40 & 154 & 96 & 31 & 903 & 2015 & 1011 \\
\hline $1993: 08$ & 52 & 18 & 119 & 111 & 17 & 1169 & 2256 & 1064 \\
\hline 1993:09 & 45 & 21 & 121 & 119 & 8 & 1246 & 2375 & 1098 \\
\hline $1993: 10$ & 63 & 23 & 118 & 93 & 16 & 1149 & 2314 & 1131 \\
\hline 1993:11 & 95 & 43 & 127 & 112 & 8 & 1177 & 2144 & 917 \\
\hline 1993:12 & 77 & 33 & 178 & 112 & 18 & 1148 & 1916 & 726 \\
\hline 1994:01 & 98 & 36 & 180 & 118 & 16 & 634 & 1545 & 879 \\
\hline 1994:02 & 82 & 19 & 171 & 221 & 12 & 605 & 1334 & 667 \\
\hline 1994:03 & 99 & 13 & 149 & 329 & 24 & 697 & 1443 & 701 \\
\hline 1994:04 & 85 & 19 & 129 & 67 & 16 & 414 & 1067 & 623 \\
\hline 1994:05 & 90 & 13 & 111 & 74 & 9 & 570 & 1251 & 653 \\
\hline $1994: 06$ & 88 & 8 & 109 & 86 & 30 & 621 & 1261 & 607 \\
\hline 1994:07 & 84 & 11 & 121 & 124 & 32 & 521 & 1287 & 727 \\
\hline 1994:08 & 69 & 4 & 122 & 102 & 17 & 632 & 1465 & 793 \\
\hline 1994:09 & 100 & 8 & 111 & 94 & 16 & 674 & 1483 & 781 \\
\hline $1994: 10$ & 100 & 18 & 112 & 132 & 16 & 740 & 1534 & 765 \\
\hline 1994:11 & 75 & 16 & 72 & 123 & 14 & 669 & 1407 & 691 \\
\hline 1994:12 & 59 & 15 & 99 & 114 & 19 & 855 & 1547 & 627 \\
\hline 1995:01 & 60 & 9 & 92 & 118 & 11 & 845 & 1521 & 628 \\
\hline $1995: 02$ & 45 & 5 & 72 & 101 & 16 & 752 & 1368 & 588 \\
\hline 1995:03 & 47 & 9 & 76 & 137 & 28 & 695 & 1436 & 658 \\
\hline 1995:04 & 34 & 16 & 59 & 122 & 12 & 436 & 953 & 475 \\
\hline 1995:05 & 65 & 8 & 77 & 144 & 4 & 580 & 1310 & 692 \\
\hline $1995: 06$ & 30 & 18 & 90 & 161 & 22 & 719 & 1496 & 714 \\
\hline 1995:07 & 40 & 11 & 110 & 109 & 16 & 680 & 1492 & 716 \\
\hline 1995:08 & 39 & 8 & 93 & 95 & 10 & 686 & 1386 & 633 \\
\hline 1995:09 & 25 & 5 & 79 & 116 & 19 & 864 & 1560 & 628 \\
\hline $1995: 10$ & 59 & 13 & 103 & 177 & 7 & 1023 & 1904 & 807 \\
\hline 1995:11 & 39 & 13 & 88 & 121 & 11 & 1269 & 2040 & 724 \\
\hline 1995:12 & 28 & 11 & 96 & 98 & 6 & 661 & 1265 & 571 \\
\hline
\end{tabular}




\section{REFERENCES}

Achermann, A. and C. Hausamman

1991 Handbuch des Asylrechts. Bern: Haupt.

Bowerman, B. L. and R. T. O'Connell

1993 Forecasting and Time Series: An Applied Approach. Belmont, CA: Duxbury Press.

Box, G. E. P. and G. C. Tiao

1975 "Intervention Analysis with Applications to Economic and Environmental Problems," Journal of the American Statistical Association, 70:70-79.

Brochmann, G.

1993 "Control in Immigration Policies: A Closed Europe in the Making." In The New Geography of European Migrations. Ed. R. King. Berlin, New York: Belhaven Press. Pp. $100-115$.

Bundesrat

1990 Botschaft zum Bundesbeschluss über das Asylvervahren (AVB) und zu einem Bundesgesetz ïber die Schaffung eines Bundesamtes für Flüchtlinge. BB1 1990(II). Bern.

Carlier, J.

1997 "One-Eyed Kings in the Land of Blinds?" In Europe and Refugees: A Challenge? Ed. J. Carlier and D. Vanheulen. Dordrecht: Kluwer.

Carlier, J. and D. Vanheule, eds.

1997 Europe and Refugees: A Challenge? Dordrecht: Kluwer.

Collinson, $S$.

1993 Europe and International Migration. London: Pinter.

Durr, R. H.

1992 "An Essay on Cointegration and Error Correction Models," Political Analysis, $4: 185-228$.

Enders, W.

1995 Applied Econometric Time Series. New York: John Wiley.

Engle, R. F. and C. W. J. Granger

1987 "Co-Integration and Error Correction: Representation, Estimation, and Testing," Econometrica, 55:251-276.

Enzensberger, H. M.

1994 Die große Wanderung. Frankfurt/Main: Suhrkamp.

Fassmann, H. and R. Münz

1994 European Migration in the Late Twentieth Century. Aldershot: Edward Elgar.

Freeman, G. P.

1992 "Migration Policy and Politics in the Receiving States," International Migration Review, 26:1114-1167.

Fuller, W. A.

1976 Introduction to Statistical Time Series. New York: John Wiley.

Fuller, W. A. and D. A. Dickey

1979 "Distribution of the Estimators for Autoregressive Time Series with a Unit Root," Journal of the American Statistical Association, 74:427-431. 
Hamilton, J. D.

1994 Time Series Analysis. Princeton, NJ: Princeton University Press.

Hammar, T.

1987 "Comparing European and North American International Migration," International Migration Review, 26:631-637.

Heckmann, F. and W. Bosswick

1995 Migration Policies. A Comparative Perspective. Stuttgart: Enke.

Hirschman, A. O.

1993 "Exit, Voice and the Fate of the German Democratic Republic: An Essay in Conceptual History,” World Politics, 45:173-202.

Hollifield, J. F.

1994 "The Migration Crisis in Western Europe: The Search for a National Model." Paper presented at the 90th Annual Meeting of the American Political Science Association, New York, September 1-4.

Holzer, T. and G. Schneider

1999 "Convergence towards Exclusion. The Schenken Agreement and the Asylum Regime in the OECD Area." In International Migration and Liberal Democracies: Yearbook Migration 1999-2000. Ed. Axel Schulte and Dietrich Thränhardt. Münster: LIT. Pp. 237-268.

Joppke, C.

1998 Challenges to the Nation-State: Immigration in Western Europe and North America. Oxford: Oxford University Press.

1997 "Asylum and State Sovereignty: A Comparison of the United States, Germany, and Britain," Comparative Political Studies, 30:259-298.

Kälin, W.

1990 Grundriss des Asylverfahrens. Basel: Helbing+Lichtenhahn.

Krell, G., H. Nicklas and Ä. Ostermann

1996 "Immigration, Asylum, and Anti-Foreigner Violence in Germany," Journal of Peace Research, 33:153-170.

Lahav, G.

1998 "Immigration and the State: The Devolution and Privatisation of Immigration Control in the EU," Journal of Ethnic and Migration Studies, 24(4):675-694.

Linder, W.

1994 Swiss Democracy: Possible Solutions to Conflict in Multicultural Societies. London: Macmillan.

Loescher, G.

1989 "Introduction." In Refugees and International Relations. Ed. G. Loescher and L. Monahan. Oxford: Oxford University Press.

MacKinnon, J. G.

1991 "Critical Values for Cointegration Tests." In Long-Run Economic Relationships: Readings in Cointegration. Ed. R. F. Engle and C. W. J. Granger. New York: Oxford University Press. Pp. 267-276.

McCleary, R. and R. A. Hay, Jr.

1980 Applied Time Series Analysis for the Social Sciences. Beverly Hills: Sage. 
McDowell, C.

1996 A Tamil Asylum Diaspora. Sri Lankan Migration, Settlement and Politics in Switzerland. Diss. Phil. I, University of Zurich. Providence/Oxford: Berghahn Books.

Miles, R. and D. Thränhardt

1995 "European Integration, Migration and Processes of Inclusion and Exclusion." In Migration and European Integration. Ed. R. Miles and D. Thränhardt. London: Pinter. Pp. $1-12$.

Money, J.

1997 "No Vacancy: The Political Geography of Immigration Control," International Organization, 51:685-720.

Nuscheler, F.

1995 Internationale Migration, Flucht und Asyl. Opladen: Leske+Budrich.

Orwin, R. G.

1997 "Twenty-One Years Old and Counting. The Interrupted Time Series Comes of Age." In Evaluation for the 21st Century. A Handbook. Ed. E. Chelimsky and W. Shadish. Thousand Oaks: Sage. Pp. 443-465.

Ostrom, C. W. and R. M. Smith

1992 "Error Correction, Attitude Persistence, and Executive Rewards and Punishments: A Behavioral Theory of Presidential Approval," Political Analysis, 4:127-184.

Risi, F. X.

1989 Univox, Jahresbericht 'Staat' 1989. Adliswil und Zürich: GfS-Forschungsinstitut und Forschungsstelle für Politische Wissenschaft, Universität Zürich.

Roggemann, H.

1993 Krieg und Frieden auf dem Balkan. Berlin: Berlin Verlag.

Thome, H.

1997 "Scheinregressionen, Kointegrierte Prozesse und Fehlerkorrekturmodelle: Eine Strategie zur Modellierung Langfristiger Gleichgewichtsbeziehungen und Kurzfristiger Effekte," Zeitschrift für Soziologie, 26:202-221.

Schneider, G. and S. Zanger

2000 "Hirschman Revisited: Asylum Seeking in Germany and Switzerland between 'Voice' and 'Exit." Unpublished Manuscript, University of Konstanz.

Spörndli, M., T. Holzer and G. Schneider

1998 "Diener dreier Herren? Kantonalbehörden und die Vollzugsvielfalt der arbeitsmarktlichen Bestimmungen im Schweizerischen Alsylrecht." Swiss Review of Political Science 4(3):53-77.

Weiner, $M$.

1995 The Global Migration Crisis. Challenge to States and to Human Rights. New York: Harper-Collins Publishers.

Zimmermann, K. F.

1996 "European Migration: Push and Pull," International Regional Science Review, 19(1 and 2):95-128. 